\title{
The Semantics of 'Spirituality' and Related Self-Identifications: A Comparative Study in Germany and the USA
}

\author{
Barbara Keller, ${ }^{a}$ Constantin Klein, ${ }^{a}$ Anne Swhajor-Biesemann, ${ }^{a}$ \\ Christopher F. Silver, ${ }^{\mathrm{b}}$ Ralph Hood ${ }^{\mathrm{b}}$ and Heinz Streib ${ }^{\mathrm{a}}$ \\ ${ }^{a}$ Research Center for Biographical Studies in Contemporary Religion, \\ Faculty for History, Philosophy and Theology, Theology Department, Bielefeld University, \\ Bielefeld, Germany \\ E-mail: barbara.keller@uni-bielefeld.de; constantin.klein@uni-bielefeld.de; \\ anne.swhajor@uni-bielefeld.de; heinz.streib@uni-bielefeld.de

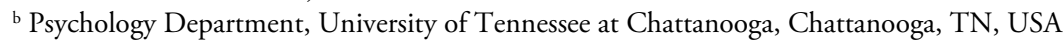 \\ E-mail: christopher-silver@utc.edu; ralph-hood@utc.edu
}

Received: 27 April 2012; revised: 4 September 2012; accepted: 26 November 2012

\begin{abstract}
Summary
Culturally different connotations of basic concepts challenge the comparative study of religion. Do persons in Germany or in the United States refer to the same concepts when talking about 'spirituality' and 'religion'? Does it make a difference how they identify themselves? The Bielefeld-Chattanooga Cross-Cultural Study on 'Spirituality' includes a semantic differential approach for the comparison of self-identified "neither religious nor spiritual", "religious", and "spiritual" persons regarding semantic attributes attached to the concepts 'religion' and 'spirituality' in each research context. Results show that 'spirituality' is used as a broader concept than 'religion'. Regarding religion, semantics attributed by self-identified religious persons differ significantly from those of the spiritual persons. The 'spiritual' and the 'religious' groups agree on semantics attributed to spirituality but differ from the 'neither spiritual nor religious' group. Qualifications of differences and agreements become visible from the comparison between the United States and Germany. It is argued for the semantically sensitive study of culturally situated 'spiritualities'.
\end{abstract}

\section{Keywords}

semantic differential, semantics, religiosity, religion, spirituality, cross-cultural

That the meaning of the term 'religion' depends strongly on the specific context of the surrounding culture is one of the fundamentals for scholars of 
religion (Ahn, 1997; Bianchi, 1994; Haußig, 1999; Schmitz, 1996). The documented cultural diversity of the semantics of the concept of religion suggests that cultural differences in meanings and connotations of basic concepts also need to be taken into account in comparative empirical studies of religiosity.

These concepts encompass not only the term 'religion' itself but also related terms, particularly 'spirituality' in recent years. The usage of the term 'spirituality' and the self-identification of being "spiritual" have become very popular in the last 30 years (to date, this popularity is even documented on Wikipedia; $c f$., http://en.wikipedia.org/wiki/Spiritual_But_Not_Religious) and inspired scientific discussions about a "spiritual turn" (Houtman \& Aupers, 2007) or even a "spiritual revolution" (Heelas, Woodhead, Seel, Szerszynski, \& Trusting, 2005). Streib \& Hood (2011) argue against the term 'spirituality' as scientific concept, suggesting taking the self-description "spiritual" very seriously. The culturally sensitive study of the semantics of labels such as 'spiritual' used for self-identification in terms of religion and worldviews is an important prerequisite for explorations of changes in the religious field.

Current international large-scale surveys illustrate that the self-identification 'spiritual' is quite common in the USA. The prevalence is lower in European countries such as Germany where a higher degree of secularity is observed: one-third of the population does not belong to a religious organization, and in the Eastern area statistics report an even higher number of people $(41.5 \%)$ who have never been members of a religious organization (Streib et al., 2009, pp. 36-42; Streib, 2008; Utsch \& Klein, 2011). Table 1 shows the differing percentages of people identifying themselves as 'More Religious than Spiritual', 'More Spiritual than Religious', 'Equally Religious and Spiritual' and 'Neither Religious nor Spiritual' in both the USA and Germany according to several representative surveys.

Although the numbers differ due to the alternative dates of assessment and operationalizations, it is clear that the majority of Americans identify as "spiritual" (and "religious"), while this is true only for one-quarter of the German population at maximum (although this percentage still signifies an increase of the 'spirituals'). These differences in numbers may point to differences in everyday discourse and semantics of religious and spiritual self-identification situated in the two different cultures. Consequently, the specific cultural semantics of both spirituality and religion should comprehensively be studied cross-culturally. The aim of this article is to compare the meanings of 'religion' and 'spirituality' in the USA and Germany. First, we will review the current state of empirical research about meanings of spirituality (in comparison to 
Table 1. Percentages of Self-Declared Religiosity and Spirituality in the USA and Germany

\begin{tabular}{|c|c|c|c|c|c|}
\hline & Data & $\begin{array}{c}\text { (More) } \\
\text { Religious* }\end{array}$ & $\begin{array}{l}\text { (More) } \\
\text { Spiritual }\end{array}$ & $\begin{array}{c}\text { Equally } \\
\text { Religious } \\
\text { and Spiritual }\end{array}$ & $\begin{array}{c}\text { Neither } \\
\text { Religious } \\
\text { nor Spiritual }\end{array}$ \\
\hline \multirow[t]{3}{*}{ USA } & GSS $2006^{* *}$ & $12.2 \%$ & $27.8 \%$ & $54.3 \%$ & $5.7 \%$ \\
\hline & $\begin{array}{l}\text { Religion } \\
\text { Monitor } \\
2008^{* *}\end{array}$ & $11.4 \%$ & $31.3 \%$ & $45.5 \%$ & $11.8 \%$ \\
\hline & $\begin{array}{l}\text { ISSP 2008/ } \\
\text { GSS 2008*** }\end{array}$ & $23.4 \%$ & $24.0 \%$ & $40.7 \%$ & $11.9 \%$ \\
\hline \multirow[t]{2}{*}{ GER } & $\begin{array}{l}\text { Religion } \\
\text { Monitor } \\
2008^{* *}\end{array}$ & $29.0 \%$ & $9.7 \%$ & $17.5 \%$ & $43.8 \%$ \\
\hline & $\begin{array}{l}\text { ISSP 2008/ } \\
\text { ALLBUS*** }\end{array}$ & $30.9 \%$ & $11.5 \%$ & $9.8 \%$ & $47.8 \%$ \\
\hline
\end{tabular}

* The wording of the items differs in the diverse surveys: some use a forced-choice item with exclusive categories while others have two separate ratings for 'being religious' and 'being spiritual' that have been cross-tabulated to calculate the reported percentages.

** Calculations based on the General Social Survey (GSS 1972-2008) and the Religion Monitor 2008 (Bertelsmann-Foundation, 2009), taken from Streib, Hood, Keller, Csöff, \& Silver (2009).

*** Calculations based on the General Social Survey (National Opinion Research Center, 2009) and the Allgemeine Bundesumfrage der Sozialwissenschaften (GESIS — Leibniz-Institut für Sozialwissenschaften, 2008), taken from Streib (in press).

those for religion) in the USA and Europe. Second, we will present design, methodology, and results of an empirical study about the semantics of both terms in the American and German context. Finally, these results will be discussed and conclusions will be drawn.

\section{Semantics of Spirituality}

Barker (2007, p. 1) aptly summarized: “... we have recently become familiar with the category 'spiritual but not religious' without knowing what this means to those who identify themselves as such". There have been few explorations into the semantics of spirituality: Zinnbauer, Pargament, Cole, Rye, Butter, Belavich, Hipp, Scott, \& Kadar (1997), who were among the first, studied 346 persons ( $32 \%$ male; age range: $15-85$ y) from various religious 
and professional backgrounds in the USA using a comprehensive design. Participants were asked to give their own definitions of religiousness and spirituality (Zinnbauer et al., 1997, p. 553). Self-identifications as "spiritual and religious" vs "spiritual but not religious" make a difference: religiousness was for more persons in the "spiritual and religious" group characterized by belief in a higher power, whereas a higher than expected number in the "spiritual but not religious" group identified religiousness with commitment to organizationally or institutionally based belief systems, with gaining extrinsic rewards, feeling superior to others or avoiding personal responsibility (Zinnbauer et al., 1997, p. 560). They also used an abbreviated form of Osgood's Semantic Differential, however, confining the report to correlational patterns of positive and negative perception (Zinnbauer et al., 1997, p. 557).

Greenwald \& Harder's (2003) study included 147 respondents (70\% female; age range: $17-59 \mathrm{y})$ in the USA with various ethnic and religious backgrounds who rated 122 adjectives according to their association with 'spiritual'/'nonspiritual' on a 5-point scale from 'definitely not spiritual' to 'definitely spiritual' and then performed a principal component analyses (PCA) to identify factors. Based on their sample of mostly New England college undergraduates, they presented the factors: Loving Connection to Others, Self-Effacing Altruism, Blissful Transcendence, and Religiosity/Sacredness. The last factor suggests an overlap with religion; however, the design of the study did not allow the exploration of this question.

Schlehofer, Omoto \& Adelman (2008) studied 64 older adults (mean age $=78.7 \mathrm{y}$ ) in three retirement communities in Los Angeles County using open-ended questions to elicit responses about the meaning, biographical past and present significance of 'spirituality' and 'religion'. Participants in this study were more likely to associate religion than spirituality with personal beliefs, community affiliation, and organized practices. Spirituality appeared to be a more abstract concept than religion that included non-theistic notions of a higher power. However, inconsistent with prior studies on non-elderly populations, spirituality was also associated with theistic concepts, suggesting some overlap of the semantics of both concepts. Due to sample size and study design, inferences from the results are limited.

These studies suggest that different meanings and connotations are attributed to the concept 'spirituality' in the USA and vary according to the subjects' own perspectives, i.e., for some people differing while for others overlapping with the concept for 'religion'. These studies have relied on various measures with different degrees of standardization and on samples compiled according to different specifications such as self-identification, religious affiliation, age, 
etc., which makes comparison between conclusions difficult. The few European studies add to the variety of methods and samples.

In a small study on 38 members of diverse religious affiliations and healthcare professions in Germany, Büssing (2006) used a sentence completion format to explore meanings and expressions ascribed to spirituality. According to his results, spirituality refers to a non-material reality, which can be sensed and gives direction how to conduct one's life.

Recently, La Cour, Ausker \& Hvidt (2012) asked 514 respondents in Denmark about their understanding of the word 'spirituality'. The respondents had to evaluate which out of a list of 115 words indicated spirituality. The sample consisted mostly of students (49\%) and professionals such as ministers from the Danish Lutheran Church and psychiatrists (67\% women; mean age $=39$ y (range: 18-78 y; $S D=15.6$ ). Factor analysis of the responses resulted in "six different understandings of spirituality: (1) positive dimensions in human life and well-being; (2) New Age-ideology; (3) an integrated part of established religious life; (4) a vague striving, opposed to religion; (5) selfishness and greediness; (6) ordinary inspiration in human activities". These characteristics are reported to relate differently to self-identifications such as spiritual $v s$ religious or believing $v s$ non-believing. The findings are limited by the specific selection of the sample.

Using the qualitative data from the Bielefeld-Based Cross-Cultural Study on Deconversion (Streib, Hood, Keller, Csoeff, \& Silver, 2009), Streib \& Keller (2007) explored the subjective understandings of 'spirituality' and 'religiosity' in relation to religious/spiritual self-identification by evaluating passages of the Faith Development Interview (Fowler, 1981; Fowler, Streib, \& Keller, 2004), especially the answers to the question: "Do you consider yourself a religious person?" Analysis of responses from members and deconverts throughout a broad range of religious communities and covering the adult age range (110 Americans and 136 Germans) showed that spirituality is characterized by "more spiritual" self-identifying research participants in the USA as referring to a non-material dimension of existence. Spirituality for them is embedded in personal experience and characterized by flexibility and openness. Spirituality for the self-identified spiritual interviewees in the German sample furthermore involves sharing respective experiences and specific practices such as meditation. Spiritual Germans reject the association of 'spirituality' with the negative cultural stereotype 'esoteric'. While the Americans who self-identified as "religious" refer to a spirituality characterized by a felt presence of God, by knowledge of God, and by spiritual goals, the 'religious' Germans see spirituality not only as experience-related but also 
as esoteric and connected to suspicious affiliations (Sekte or 'cult' used in a negative sense).

The modest conclusion drawn from these few and varied studies in the USA and Europe indicates cultural differences and matters of self-identification. Therefore, we need to be specific about what concepts such as 'spirituality' mean for both the individual or the group in a particular cultural context. For more systematic cross-cultural comparisons of culturally situated identifications we need a tertium comparationis, a common standard to assess meanings and connotations, which provides the opportunity for a comparison that is both semantically sensitive and systematically quantifiable.

In previous studies, different measurement methods have been used to assess the meaning(s) of spirituality: semantic differentials, word lists, sentence completion tasks, and interview techniques. Among these, the semantic differential best meets the demands of systematic cross-cultural study of meanings because it has the highest degree of standardization. Other semantically sensitive, standardized methods would be grid techniques (for the religious sphere: e.g., Emmons, 1999; Huber, 2002) or Q-sort tasks (e.g., Wulff, 2009). However, the semantic differential has been widely used within research about religious topics; e.g., religious experiences (Brody, 1965), identities (Hofman, 1970), symbols (Craddick, Thumin, \& Barclay, 1971), buildings (Daiber, 2001), or public figures (Hood, Morris, Hickman, \& Watson, 1995). Further topics from the religious sphere which have been assessed using semantic differentials are God images (Benson \& Spilka, 1973; Broughton, 1975; Francis, Robbins, \& Gibson, 2006), dogmatism (Hood, 1973; 1974), or other religious attitudes (Muthen, Olsson, Pettersson, \& Stahlberg, 1977). Thus, semantic differentials are well established as measurement method within the psychology of religion. Additionally, semantic differentials have been recommended (Heise, 2010; Osgood, 1972) and widely used (Osgood, May, \& Miron, 1975; cf., Heise, 2010, for an overview) for cross-cultural psychological research. Because of their applicability for both cross-cultural research and research on religion, we decided to conduct our cross-cultural analyses of the semantics of 'spirituality' and 'religion' on the basis of semantic differentials.

Our research question is thus: Can we identify profiles of the semantics of 'spirituality' and 'religion', which differ by cultural context and by self-identifications as spiritual, religious, or neither? 


\section{Present Study}

\section{Background}

Our study on spirituality is based on a large and diverse sample of participants $(n=1886)$ in the United States and Germany. For the systematic study of semantics we used, among other methods, the semantic differential, which has been developed and used in cross-cultural research by Osgood (1962; Osgood, May, \& Miron, 1975; Snider \& Osgood, 1969; cf., Heise, 2010). In Germany, the semantic differential has been introduced as profile of polarities (Polaritätenprofil, Hofstätter, 1957).

The design of our study consists of questionnaire data, personal interviews, and an experimental task. The questionnaire includes, besides demographics and space for free-text entries of respondents' definitions of religion and spirituality, Hood's (1975) Mysticism Scale, the Big Five (NEO-FFI, Costa \& McCrae, 1985), Granqvist's (2002) Attachment Items, Exline's Attitudes toward God Scale (Wood, Worthington, Exline, Yali, Aten, \& McMinn, 2009), Ryff's Psychological Well-Being and Growth Scale (Ryff 1989; Ryff \& Singer, 1998), the Loyola Generativity Scale (McAdams \& de St. Aubin, 1992), and the Religious Schema Scale (Streib, Hood, \& Klein, 2010). These measures allow further profiling of self-identifications and their correlates.

Here we report the analyses of the semantics of 'spirituality' and of 'religion' based on (a) Osgood's (1962) Semantic Differential and (b) on a selfconstructed Contextual Semantic Differential (detailed in the measurement section below), because we are also interested in the specific contextual denotations of the terms 'spirituality' and 'religion'. Osgood, distinguishing between connotations and denotations, endorsed the creative use of his method: "From the standpoint of the practice of semantic measurement, this means that there is no such entity as 'The Semantic Differential', with a rigidly defined set of factors-except perhaps in the sense of a common denominator from which more specific instruments are to be derived" (Osgood, 1962, p. 24; see also Osgood, 1972, p. 35). Thus, in addition to Osgood's 18-item measure, covering the dimensions of $E$ (evaluation), $P$ (potency), and $A$ (activity), we have constructed a Contextual Semantic Differential with 30 pairs of opposite adjectives as items to assess how 'religion' and 'spirituality' are located in their specific semantic contexts. We used, with the Osgood version, opposites such as 'nice-awful', 'weak-strong', and 'fast-slow' to be rated on a 5-point scale with regard to 'spirituality' and to 'religion'. For the contextual version 
we offered opposites such as 'liberating-oppressive', 'modern-traditional', 'sacred-profane'.

\section{Procedure}

Osgood's (1962) Semantic Differential and our 30-item Contextual Semantic Differential were part of our bilingual questionnaire in Germany and the USA. Persons of different religious affiliations and worldviews and across the adult life span in Germany and the USA have responded to invitations and advertisements which were sent out using primarily internet communication. Opting for diversity, we took care to address different websites and internet platforms dedicated to discussions on religious and secular worldviews. We monitored advertisement success by asking participants how they learned about our research. Selected print media were also addressed. Paper versions of the questionnaire were used to include for instance elderly citizens without internet access. In the USA the sampling strategy also included radio and TV-stations.

The online questionnaire has been hosted on the server of unipark (www. unipark.de). Most participants answered the survey questions online. Data were exported to local computers as SPSS files. Pencil-and-paper questionnaires were entered into the dataset. Data cleaning involved the elimination of ca. $20 \%$ cases for persons who did not answer entire parts of the questionnaire or cases for which our conservative rule for missing replacement (replacing single missing responses by individual sub-scale means) could not be applied. All following analyses were performed using SPSS 19 and 20.

\section{Participants}

Here we report on the data sub-set of those respondents sampled ( $n=1082$ Americans, $n=703$ Germans) who did complete all bipolar scales of the semantic differentials. ${ }^{1}$ In the American sample, ages range from 15 to 82 years $(M=34.23, S D=14.50)$ and in the German sample from 16 to 90 years $(M=42.03, S D=13.56)$. Of the American and German respondents sampled, $62.75 \%$ and $55.90 \%$ are female, respectively, which might be a consequence of self-selection during the sampling process, because women are known to express greater interest in spiritual and religious issues (Francis, 1997; Hood,

\footnotetext{
1) A total of 1886 respondents ( $n=1113$ Americans and $n=773$ Germans) have filled in the questionnaire in such a way that their data can be used in most analyses. Not all respondents completed the semantic differentials, however. A few participants reported that they sometimes felt the semantic differentials to be awkward (Bortz, \& Döring, 2006, p. 184). Although we offered an anticipatory instruction, this task was skipped by $9 \%$ of the German and $2 \%$ of the American respondents.
} 
Hill, \& Spilka, 2009; Woodhead, 2007). Mean per capita income for the German sample is 38,875 USD $(S D=25,899)$, and for the American sample 40,575 USD $(S D=28,103)$. Comparison with OECD data (OECD, 2011; OECD, 2011-12) indicates that a much higher percentage of well-educated respondents from both countries are found in our data $(96.30 \%$ in the American sample and $80.51 \%$ in the German sample have an upper secondary or tertiary education), while lower-educated people are under-represented which might also be due to the sampling process.

For further typological analyses reported in this article, data were split according to their self-identification into three sub-groups: Highly Spiritual, Low Religious (HSLR), Highly Religious (HR), or Neither Spiritual nor Religious (NSNR) (see Table 2). Expecting that these sub-groups would reveal characteristic differences in their semantic differentials, we constructed them based on two continuous 5-point ratings assessing the degree to which participants describe themselves as "spiritual" and/or "religious". The HSLR sub-group consists of participants with a score of 4 or 5 on the Not SpiritualSpiritual scale and a score of 1 or 2 on the Not Religious-Religious scale. The HR group consists of participants with a score of 4 or 5 on the Not ReligiousReligious scale. Only a minority of these HR participants have rated as low as 1 or 2 on the Not Spiritual-Spiritual scale (corresponding to survey results in the USA; $c f$. Table 1). Therefore we decided to include respondents with a score higher than 2 on the 'spirituality' rating in this sub-group. This means, however, that this HR sub-group is not exactly mirroring the HSLR group. Finally the NSNR group consists of those respondents with a score of 1 on both ratings. This grouping offers the opportunity to make comparisons on a satisfying empirical basis. Finally, our sub-samples for the typological analyses are made up of Americans $(n=805)$ and Germans $(n=551)$. Sizes of the three sub-groups by country are detailed in Table 2 .

Table 2. Proportions of Sub-Groups

\begin{tabular}{lrcr}
\hline Sub-Groups & \multicolumn{2}{c}{ Country } & Total \\
& (USA) & (Germany) & \\
\hline Highly Spiritual, Low Religious & 296 & 258 & 554 \\
Highly Religious & 406 & 177 & 583 \\
Neither Spiritual nor Religious & 103 & 116 & 219 \\
Sub-Total & 805 & 551 & 1,356 \\
$\quad$ Not in sub-groups & 277 & 152 & 429 \\
Total & 1,082 & 703 & 1,785 \\
\hline
\end{tabular}


The sexes are differently distributed among the three sub-groups, but the distributions within both sub-samples resemble each other: about two-thirds of the HSLR group are women (USA, 66.2\%; GER, 60.5\% female). This also holds for the 'religious' groups in both sub-samples (USA, 65.0\%; GER, $65.0 \%$ female). The majority of the NSNR group was male in both subsamples (USA, 44.7\%; GER, 30.2\% female). This is a significant difference $\left(\chi_{\mathrm{USA}}^{2}=16.86, p<.001 ; \chi_{\mathrm{GER}}^{2}=39.14, p<.001\right)$, again corresponding to the finding that more women than men are attracted by spirituality and religion. The relationships between self-identifications and age, income, and education have been explored using one-way ANOVAs and post hoc tests using Scheffe's procedure. In the American sub-sample no significant differences were found between the groups with respect to age, income or education. For the German sub-sample, the NSNR group was found to be significantly younger $\left(F_{(2)}=\right.$ $7.99, p<.001)$ and better educated $\left(F_{(2)}=5.81, p=.003\right)$.

\section{Measures}

To explore the semantics of spirituality, we have included one of Osgood's (1962; Snider \& Osgood, 1969) classical semantic differentials. We used the 18-item version presented in Osgood (1962, p. 16). The merits of this method have been corroborated specifically for cross-cultural use by Osgood, May, \& Miron (1975). It assesses three dimensions/factors of Evaluation (E: nice-awful, fine-coarse, heavenly-hellish, smooth-rough, mild-harsh, clean-dirty), Potency ( $P$ : big-little, powerful-powerless, strong-weak, longshort, full-empty, many-few) and Activity (A: burning-freezing, hot-cold, fast-slow, sharp-dull, light-dark, young-old).

Because we were also interested in a more sensitive exploration of patterns of denotations in the semantic contexts of religion and spirituality, in line with Osgood's own reasoning reported above, and as recently discussed by Heise (2010), we developed an additional Contextual Semantic Differential for the exploration of both spirituality and religion. This Contextual Semantic Differential consists of 30 pairs of oppositional adjectives which refer to 'religion' and 'spirituality' (sample items: 'this worldly-other worldly', 'secularholy'). For the construction of our Contextual Semantic Differential, we created an item pool of descriptives for religion and spirituality, collected in Germany and in the USA; thereby we used dictionaries and published lists of adjectives referring to religion and/or spirituality such as the Religion/Spirituality Words from LIWC-2007 from the Pennebaker Laboratory. ${ }^{2}$ 2) (http://homepage.psy.utexas.edu/homepage/Faculty/Pennebaker/Home2000/JWPhome
.htm http://www.liwc.net/ and personal communication). 
The final set of adjective pairs has been selected by an expert rating of our bilingual and bicultural research team to ensure cross-cultural comparability as well as embeddedness in each cultural context. This resulted in parallel American and German versions of the Contextual Semantic Differential.

With both Osgood's Differential and the Contextual Semantic Differential, the same stimuli ('religion' and 'spirituality') were offered in the same format and with the same instructions. Thus we have four blocks of semantic differentials, which allow the juxtaposition of the semantic associations of 'religion' and 'spirituality' on the same adjective polarities. All in all, we have a $2 \times 2 \times 2$ design ('religion'/'spirituality' $\times$ Osgood's Differential/Contextual Semantic Differential $\times$ USA/Germany).

\section{Results}

\section{Semantic Differentials according to Osgood}

We first present the Osgood Differential and then the Contextual Semantic Differential. We start with an analysis of the semantic field of 'spirituality' and 'religion' as visualized by scatter plots with Spirituality and Religion as $x$ and $y$ axes. Fig. 1 presents scatter plots for both the American and German subsamples. The scatter plots are based on the Osgood Differentials, and data are based on means calculated from paired $t$-tests. The paired $t$-tests were calculated $(C I=.95)$ to assess the differences between the means for 'religion' and 'spirituality' on each adjective pair. Within the scatter plots, however, the means for 'religion' and 'spirituality' are interpreted as vectors indicating the affinity of each adjective pair to the poles for the terms 'religion' and 'spirituality'. For easier reading, only the positive pole of the adjective pairs is included in Fig. 1; for the opposite poles, see Figs. 2-4.

The scatter plots for the Osgood differentials indicate a difference between the American and German respondents. Those in the USA appear to see less difference between spirituality and religion, since most data clearly assemble in the upper-right field segment, displaying the majority of adjectives for Osgood's (1962) dimensions $P$ ('big', 'powerful', 'strong', 'long', 'full', 'many') and $A$ ('burning', 'hot', 'sharp', 'light') for the characterization of spirituality and religion. 'Spirituality' is also associated with 'smooth', 'fine', 'mild' (belonging to Osgood's dimension $E$ ), and 'young' $(A)$, while 'fast' (lower-left segment: $A$ ) is associated with neither 'spirituality' nor 'religion', and there is no single characteristic which is associated exclusively with religion (lowerright segment is empty). The latter is also the case for the German sub-sample. In the scatter plot for the German sample, however, we see less overlap between 

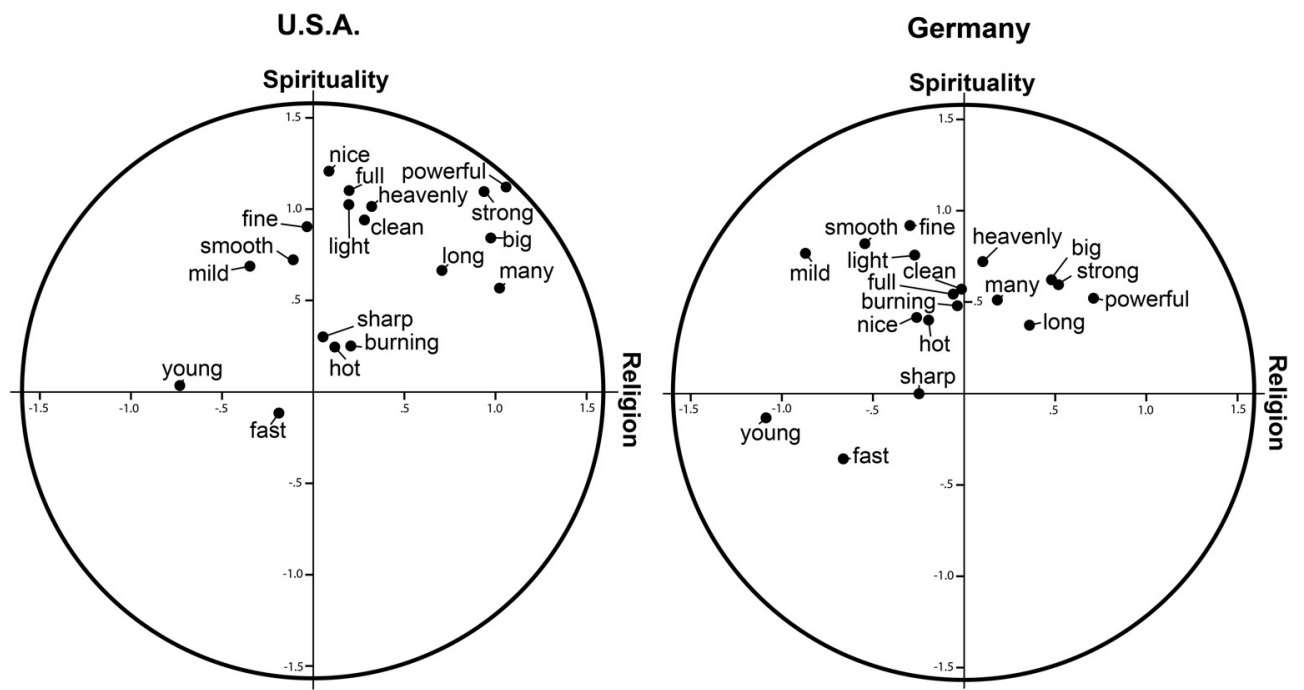

Fig. 1. The Semantic Field of 'Spirituality' vs 'Religion' (Osgood Differentials). Here, the semantic field is visualized as scatter plot for each sub-sample, based on Osgood's Semantic Differential. The scatter plots display a vector space spanning between 'religion' and 'spirituality', locating the single adjectives according to their position relative to both concepts, highlighting general trends for Germany and the USA.

Note. The position of the dots is determined by the means for "spirituality" (y) and religion" (x) resulting from a paired t-test with Osgood's semantic differential items in the U.S. $(n=1802)$ and German $(n=703)$ samples.

'spirituality' and 'religion'. First, most of the $P$-items describe both concepts (right-upper segment), but less pronounced than in the American sub-sample. Second, most $A$-items ('burning', 'hot', 'sharp', 'light') fall into the upper-left segment, describing spirituality alone. Taken together, these scatter plots indicate that the semantic of 'spirituality' has positive evaluative connotations for both the American and German samples, and the more exclusive ascription of power to spirituality by German respondents accounts for the fact that spirituality seems to be semantically more distinct from religion for respondents in the German sub-sample. Next, we turn to the sub-groups and their polarity profiles, also displayed by country.

\section{Typological Comparisons-Osgood Differentials}

For Osgood's Semantic Differential, paired $t$-tests were calculated $(C I=.95)$ to assess the differences between the means for 'religion' and 'spirituality' on 
B. Keller et al. I

Archive for the Psychology of Religion 35 (2013) 71-100

USA
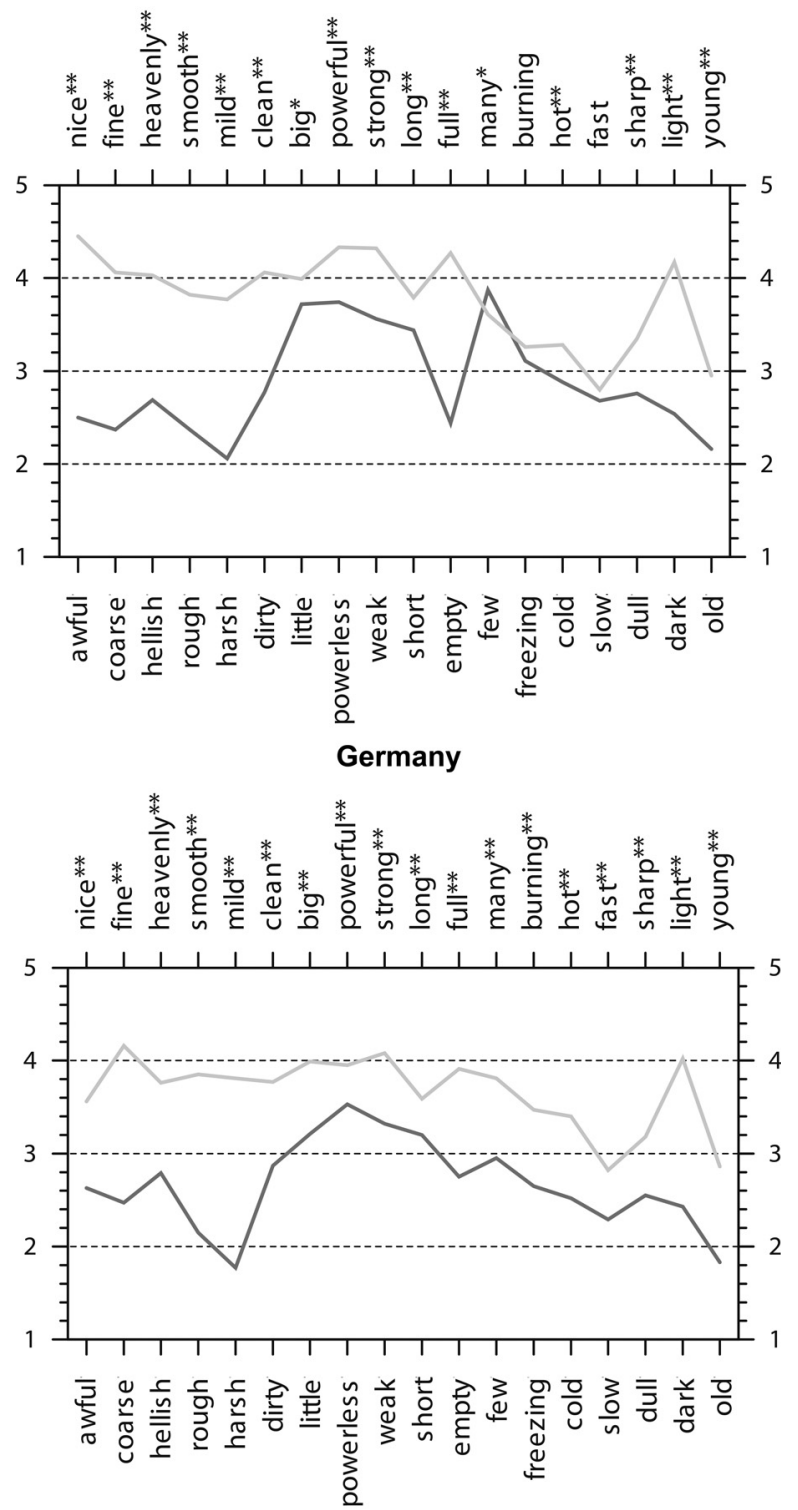

Fig. 2. Highly Spiritual, Low Religious (Osgood Differentials). The black line shows the polarity profile of 'religion', the grey line shows the polarity profile of 'spirituality' for the comparison of the American vs German subgroup of the respondents self-identifying as Highly Spiritual, Low Religious (HSLR). The asterisks show the levels of significance for each paired $t$-test:

$$
{ }^{* *} p<.001,{ }^{*} p<.05 \text {. }
$$




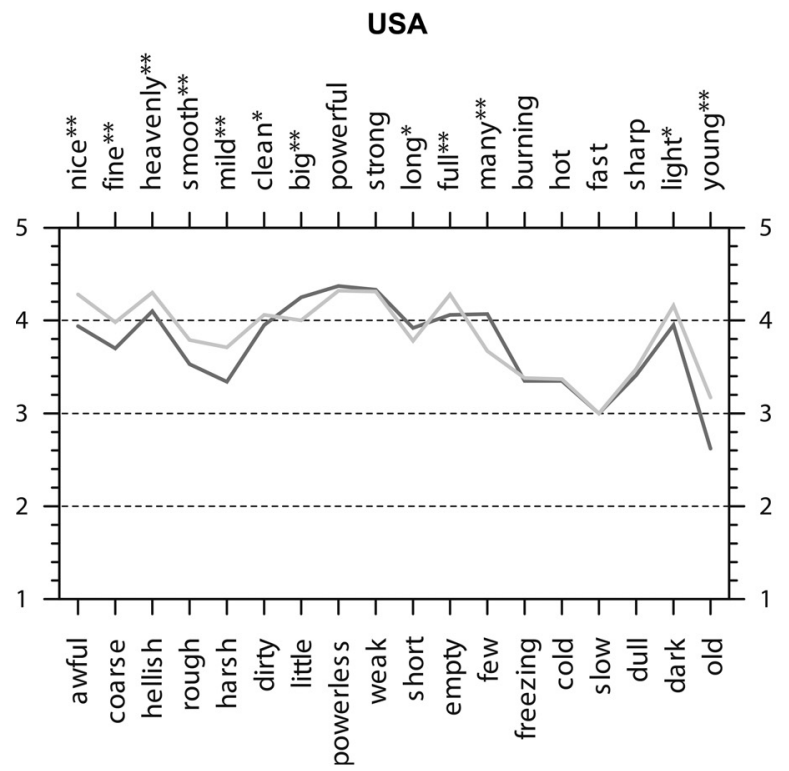

\section{Germany}

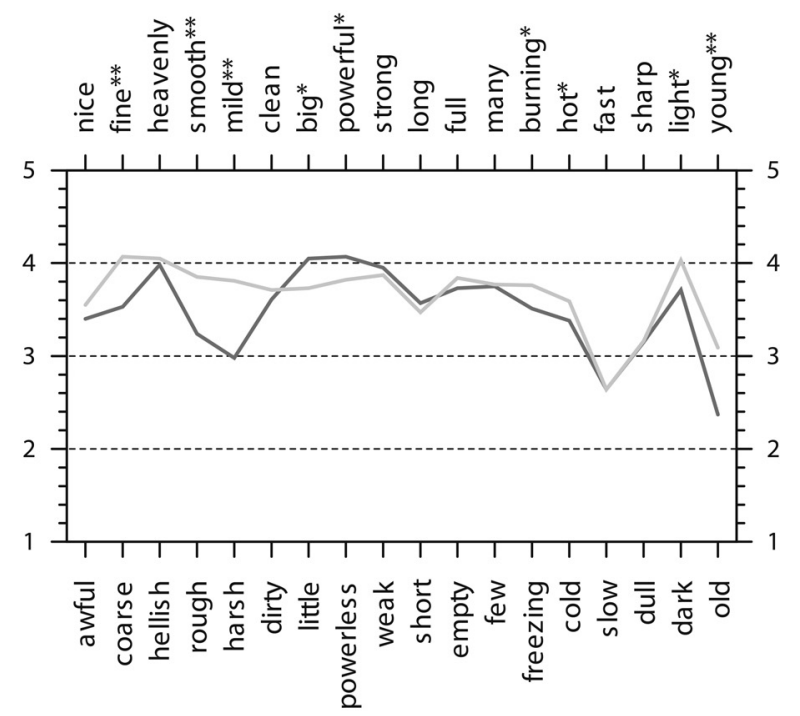

Fig. 3. Highly Religious (Osgood Differentials). The black line shows the polarity profile of 'religion', the grey line shows the polarity profile of 'spirituality' for the comparison of the American vs German sub-group of the respondents self-identifying as Highly Religious (HR). The asterisks show the levels of significance for each paired $t$-test: ${ }^{* *} p<.001,{ }^{*} p<.05$. 
each adjective pair. These paired $t$-tests were calculated with the American and German data sets split into the three sub-groups that have been constructed to assess differences between the Highly Spiritual, Low Religious (HSLR), the Highly Religious (HR), and the Neither Spiritual nor Religious (NSNR) respondents. In the figures, we display the results pairwise for both terms, comparing the responses of the three groups from the American sub-sample with those from the German sub-sample. The items for the Osgood differentials are presented in Figs. 2-4 in the order of the three dimensions $E, P$, and $A$ which Osgood detected by factor analyses in his studies (e.g., Osgood, 1962).

In our data, the $E-P$ - $A$ factor structure could be corroborated, even if not perfectly, by PCA with Varimax rotation with respect both to the eigenvalues and the scree plots. For the term 'religion' in both sub-samples, the three identified factors strongly resembled those of Osgood and explained $65.48 \%$ of the variance within the American sub-sample and $62.92 \%$ of the variance within the German sub-sample. For 'spirituality', only the first two factors, $E$ and $P$, could roughly be replicated in both sub-samples, while the third factor, $A$, could not be identified. Instead, in both the American and German subsamples, the analyses suggest a 4-factor solution with respect to both eigenvalues and scree plots, explaining $60.39 \%$ of the variance within the American sub-sample and $61.53 \%$ of the variance within the German sub-sample. The third and fourth factors, however, in each sub-sample consisted only of two pairs of words. All in all, for the term 'spirituality', Osgood's factors seem to be only approximately replicable. Therefore, the following presentation and discussion of results is not primarily based on the factor structure but rather focuses on the polarity profiles for the three sub-groups. Nevertheless, the adjective pairs are sorted according to Osgood's $E-P-A$ factor structure.

For the Highly Spiritual, Low Religious (HSLR) Americans and Germans, 'spirituality' gets a rather positive evaluation (E-dimension; e.g., 'nice', 'fine', 'mild'), compared to 'religion', which is not only shown by significant differences but also indicated by the trajectories of the lines indicating 'religion' and 'spirituality' above and below of the midline $(3=$ 'neutral' in the 5-point rating). Also on the P-dimension, 'spirituality' is perceived by the HSLR respondents as more powerful (e.g., 'powerful', 'strong') than 'religion'. On the $A$-dimension, (e.g., 'burning', 'hot', 'fast', 'sharp'), 'spirituality' is closer to the neutral line with smaller, although in most cases still significant, differences between 'spirituality' and 'religion', in particular in the American sub-group.

For the Highly Religious (HR) groups, the polarity profiles are much closer aligned, which may indicate very similar semantics for both religion and spirituality for these groups (although there are still some significant mean 


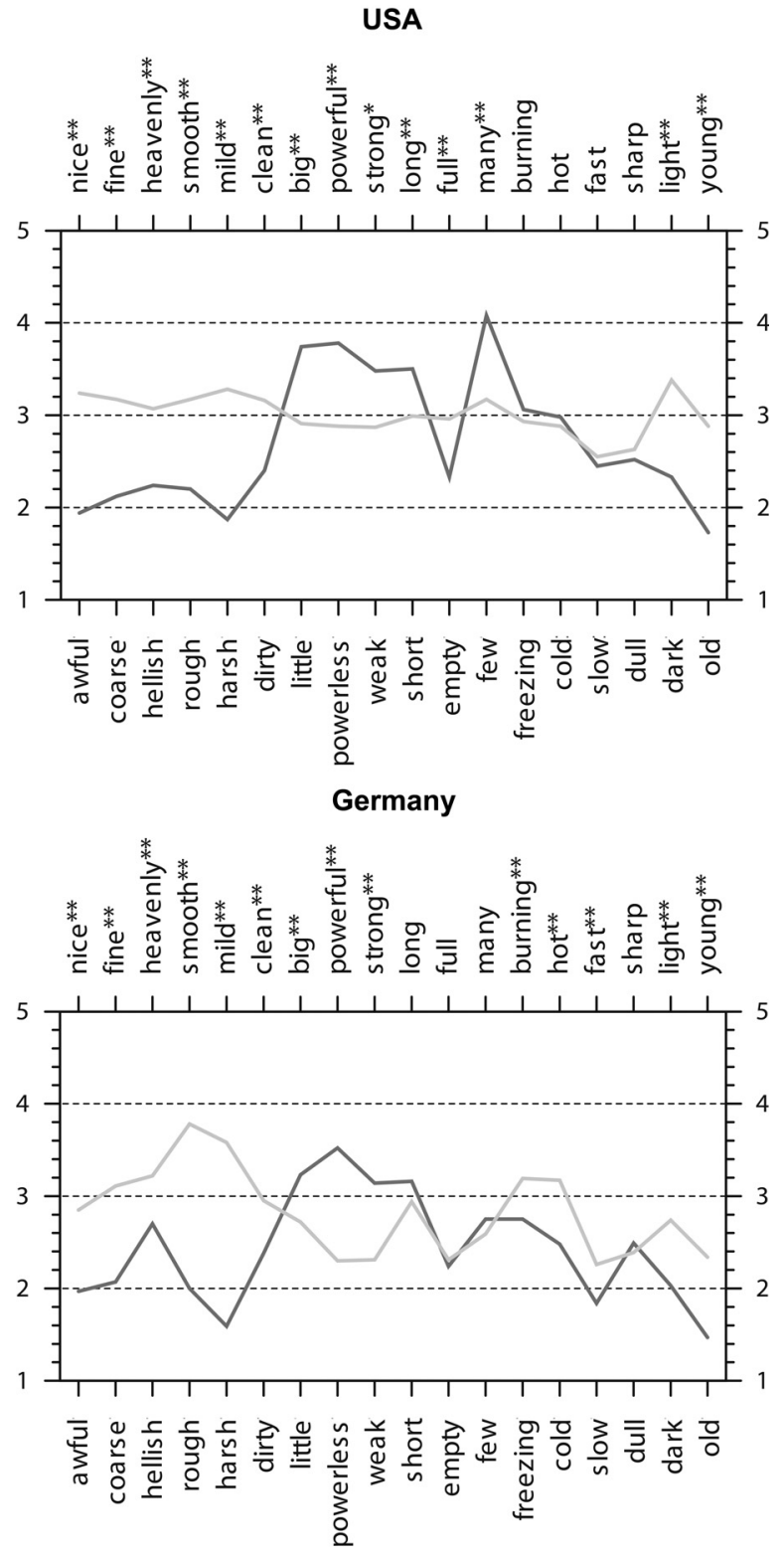

Fig. 4. Neither Spiritual nor Religious (Osgood Differentials). The black line shows the polarity profile of 'religion', the grey line shows the polarity profile of 'spirituality' for the comparison of the American vs German sub-group of the respondents self-identifying as Neither Spiritual nor Religious (NSNR). The asterisks show the levels of significance for each paired $t$-test: ${ }^{* *} p<.001,{ }^{*} p<.05$. 
differences). The profiles - most clearly for the dimensions $E$ and $P$ - for 'spirituality' and 'religion' are both located on the upper part of the diagram, which indicates positive associations. While this pattern applies to the responses of the HR sub-groups of both the American and German sub-samples, it seems more pronounced for the Americans. Spirituality in the HR sub-groups is associated with connotations such as 'mild' and 'smooth', while religion appears as a bit rougher and harsher. A further cultural parallel is that spirituality is perceived as a bit younger and lighter.

Respondents in the Neither Spiritual nor Religious (NSNR) groups in the German and American sub-samples indicate a more or less neutral judgment of spirituality, which is more pronounced among the Americans and tends more to the negative poles among the Germans. For 'religion', however, an interesting pattern emerges in both cultures: in the $E$ section, 'religion' is located on the negative side and associated with 'awful', 'coarse', 'rough', and 'harsh'-a view shared by the Highly Spiritual, Low Religious (HSLR) subgroups (see above), to whom religion also looks empty, compared to spirituality. In the $P$ section, however, 'religion' is seen as more powerful, bigger and stronger in comparison to 'spirituality', a view shared by the Highly Religious (HR) sub-groups.

Taken together, our analyses with Osgood's Semantic Differential present 'spirituality' and 'religion' as rather fluid terms with considerable differences depending on who is using them. If we look at the $E$ dimension, in all three sub-groups, 'spirituality' is evaluated more positively than 'religion'. Focussing on the polarity profiles, however, and on single significant polarities, differences between our three sub-groups become visible: to the Highly Spiritual, Low Religious (HSLR) sub-group, spirituality is more powerful while to the Highly Religious (HR) sub-group, the power is with religion. Differences by country also have been noted, most importantly for the perception of spirituality by the Neither Spiritual nor Religious (NSNR) respondents: the American respondents take a neutral stance, while the Germans in this sub-group rate spirituality more negatively. The exploration of specific polarity profiles will be expanded with the contextual differentials.

\section{Contextual Semantic Differentials}

To explore the semantic fields of 'spirituality' and 'religion' in their associations with content and context, we have constructed the 30-item Contextual Semantic Differential. Again, the presentation of results starts with portraits of the semantic fields (scatter plots with Spirituality and Religion as axes) as they emerge from each national sub-sample of our data, and continues with polarity 
profiles that emphasize differences according to country and sub-group. These results are based-again—on paired $t$-tests $(C I=.95)$ run separately for the German and American sub-samples.

Here, the semantic field is visualized as scatter plot for each sub-sample, based on our Contextual Semantic Differential. Again, for easier reading, only the positive poles of the adjective pairs are included; for the opposite poles refer to the following Figs. 6-8.

As presented in Fig. 5, the strongest and more exclusive associations with spirituality in both the American and German sub-samples are represented by adjectives such as 'creative', 'liberating', 'flexible', and 'individual'. For 'religion', there are no exclusive associations (lower-right segment is empty),

U.S.A.

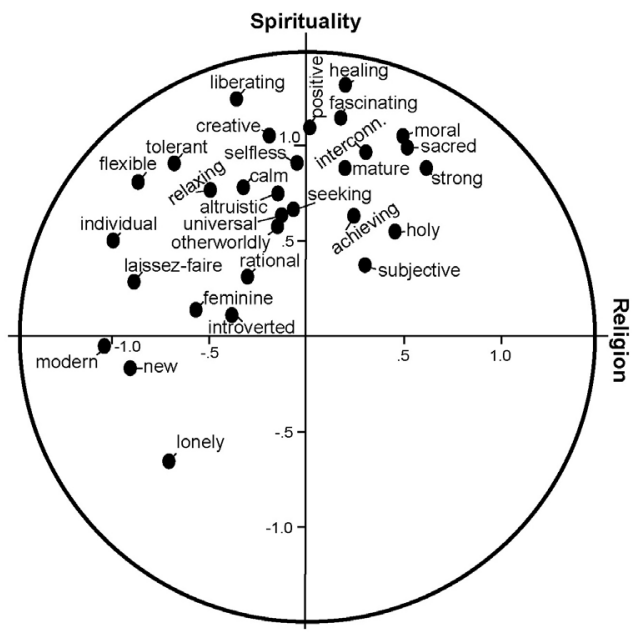

Germany

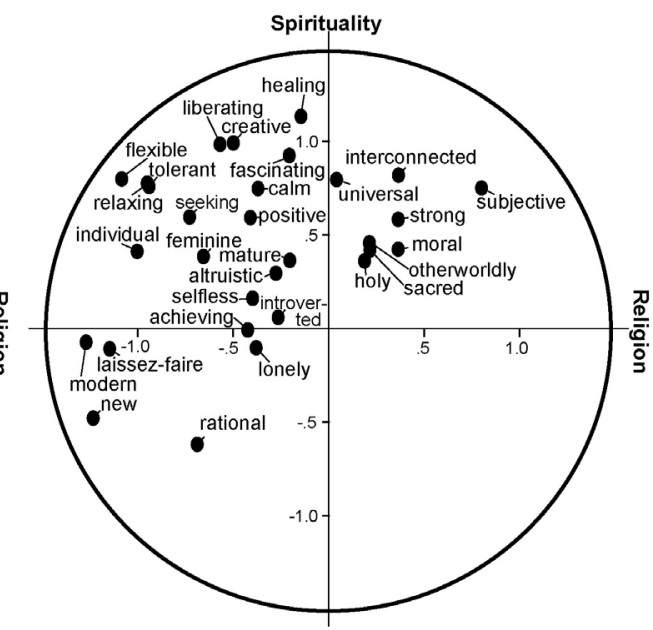

Fig. 5. The Semantic Field of 'Spirituality' vs 'Religion' (Contextual Differentials). Here, the semantic field is visualized as scatter plot for each sub-sample, based on our Contextual Semantic Differential, displaying a vector space spanning between 'religion' and 'spirituality'. By locating the single adjectives according to their position relative to both concepts, general trends regarding shifts of the semantics of both concepts become visible for each research context.

Note. The position of the dots is determined by the means for "spirituality" (y) and "religion" (x) resulting from a paired t-test with the contextual semantic differential items in the U.S. $(n=1802)$ and German $(n=703)$ samples. 
closest to a characterization of 'religion' are the adjectives 'subjective' in the American sample, and 'holy', 'sacred', and 'moral' in the German sub-sample in the upper-right segment, which indicates, however, overlap with 'spirituality'. In the German sub-sample, 'interconnected' and 'subjective' characterize both 'spirituality' and 'religion'. In the American sample, both are characterized by 'achieving', 'mature', 'fascinating', 'healing', and 'positive' adjectives, which, for the German sub-sample, fall on the 'spiritual'-only side (upper-left segment) of the scatter plot. In both samples, 'strong', 'moral', and 'sacred' are indicators for both 'spirituality' and 'religion'. Adjectives that are least associated with both 'religion' and 'spirituality' assemble in the lower-left segment; to these belong 'new', 'modern', 'lonely' and, for the German sample, also 'laissez-faire' and 'rational'-displaying the Germans' more critical view. For both the American and German sub-samples, it seems that 'religion' per se is barely visible. Rather, where it spreads across associations, it overlaps with 'spirituality'. 'Spirituality', however, is characterized by the broad majority of associations in both samples and by different intersections with 'religion'.

\section{Typological Comparisons-Contextual Differentials}

We also attempted to calculate the PCAs for the Contextual Semantic Differentials, but neither orthogonal (Varimax) nor oblique (Oblimin) rotations offered acceptable factors solutions. In the American and German samples, we could only detect one large factor including 15 or 16 of the chosen pairs of adjectives for 'spirituality' as well as for 'religion'. Those which did not load on the first factors did not correlate strongly enough with other pairs to form additional factors based on more than two items. Although these results might seem discouraging at first sight, they could also be understood as an indication of the complexity and diversity of meanings associated with the terms 'spirituality' and 'religion'. In particular, the use of the term 'spirituality' in daily communication may be associated with an increase of diverging semantics. With respect to the findings presented in our scatter plots, the factor analyses for 'religion' might also indicate a loss of meaning for the term 'religion', which might go along with difficulties in finding precise factorial solutions as well. Both processes might inhibit clear factorial solutions. Due to the lack of factorial solutions, we decided to set dimension reduction procedures aside and to illustrate the results for the Contextual Semantic Differentials by presenting the pairs of adjectives in order of the size of the mean differences between 'spirituality' and 'religion' in the overall samples 

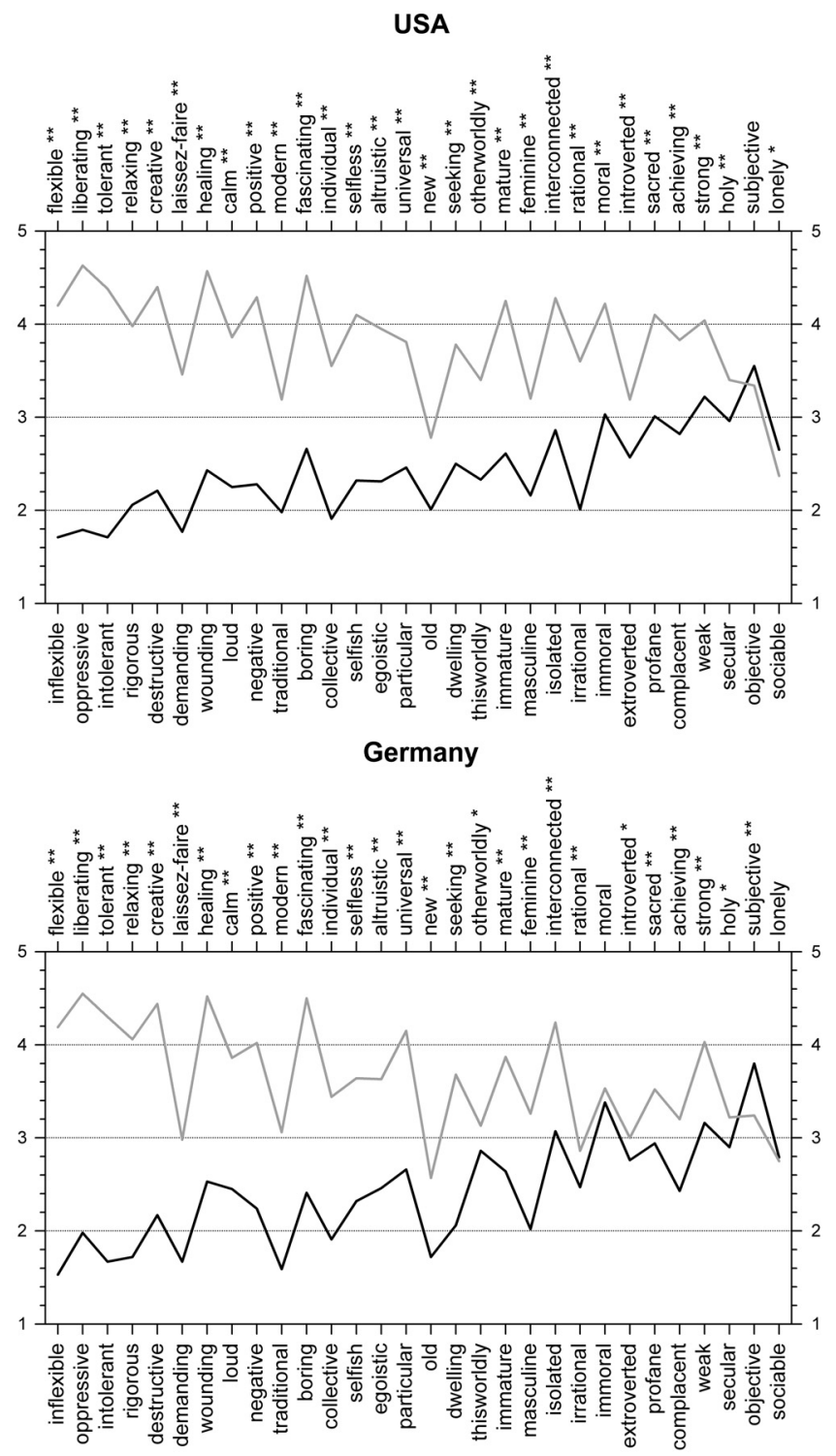

Fig. 6. Highly Spiritual, Low Religious (Contextual Differentials). The black line shows the polarity profile of 'religion', the grey line shows the polarity profile of 'spirituality' for comparison of the American vs German sub-groups of the respondents self-identifying as Highly Spiritual, Low Religious (HSLR). The asterisks show the levels of significance for each paired $t$-test:

$$
{ }^{* *} p<.001,{ }^{*} p<.05 \text {. }
$$


(cf., Figs. 6-8). We will again focus on the profiles rather than on possible dimensions of concept evaluation. Again, we start with the self-identified Highly Spiritual, Low Religious (HSLR) respondents in the American and German sub-samples.

For the Highly Spiritual, Low Religious (HSLR) American and German sub-groups we see 'spirituality' in the upper half of the diagram, 'religion' in the lower half, or on different sides of the midline. The respondents in this HSLR sub-group see the largest differences between religion and spirituality. Spirituality is perceived as 'flexible', 'liberating', and 'creative', while religion is seen as 'oppressive', 'intolerant', and 'rigorous'. Interestingly, 'religion' is seen a bit closer to the 'subjective' pole of 'objective-subjective'.

The responses of both the German and American Highly Religious subgroups result in different profiles compared to those of the Highly Spiritual, Low Religious (HSLR) sub-groups. Here, the polarity profiles do not differ so much but rather look like parallel zigzags (although, again due to the sample size, many differences are significant). 'Religion' and 'spirituality' are both portrayed as 'liberating', 'tolerant', 'creative', 'positive', 'fascinating' with 'spirituality' even closer to these poles. Plausible differences concern the closer association of 'religion' with 'traditional', 'collective', 'old', 'masculine', 'extroverted', and 'sociable'. In both sub-samples, although more pronounced in the German sub-sample, 'spirituality' is closer to the 'irrational' pole of the 'rational-irrational' polarity.

Those Americans who self-identify as Neither Spiritual nor Religious (NSNR) seem to make more of a difference between these constructs than the Highly Religious (HR) sub-group but less than the Highly Spiritual, Low Religious (HSLR) sub-group. They perceive religion as more negative and spirituality as rather neutral (zigzags across the midline), while both religion and spirituality are seen as irrational.

Germans who identify neither with religion nor with spirituality display more negative impressions of both, with 'spirituality' and 'religion' leaning toward the 'oppressive' and 'intolerant' poles. Both 'religion' and 'spirituality' are seen as 'irrational', 'immature', and highly 'subjective', which is more pronounced in the German compared to the American Neither Spiritual nor Religious (NSNR) sub-group. The strongest difference between NSNR Americans and Germans appears to concern their perception of the concepts 'religion' and 'spirituality' as 'this worldly' or 'other worldly', while the Americans evaluate both concepts as more or less neutral, the German Neither Spiritual nor Religious (NSNR) sub-group identifies them as clearly 'otherworldly'. 

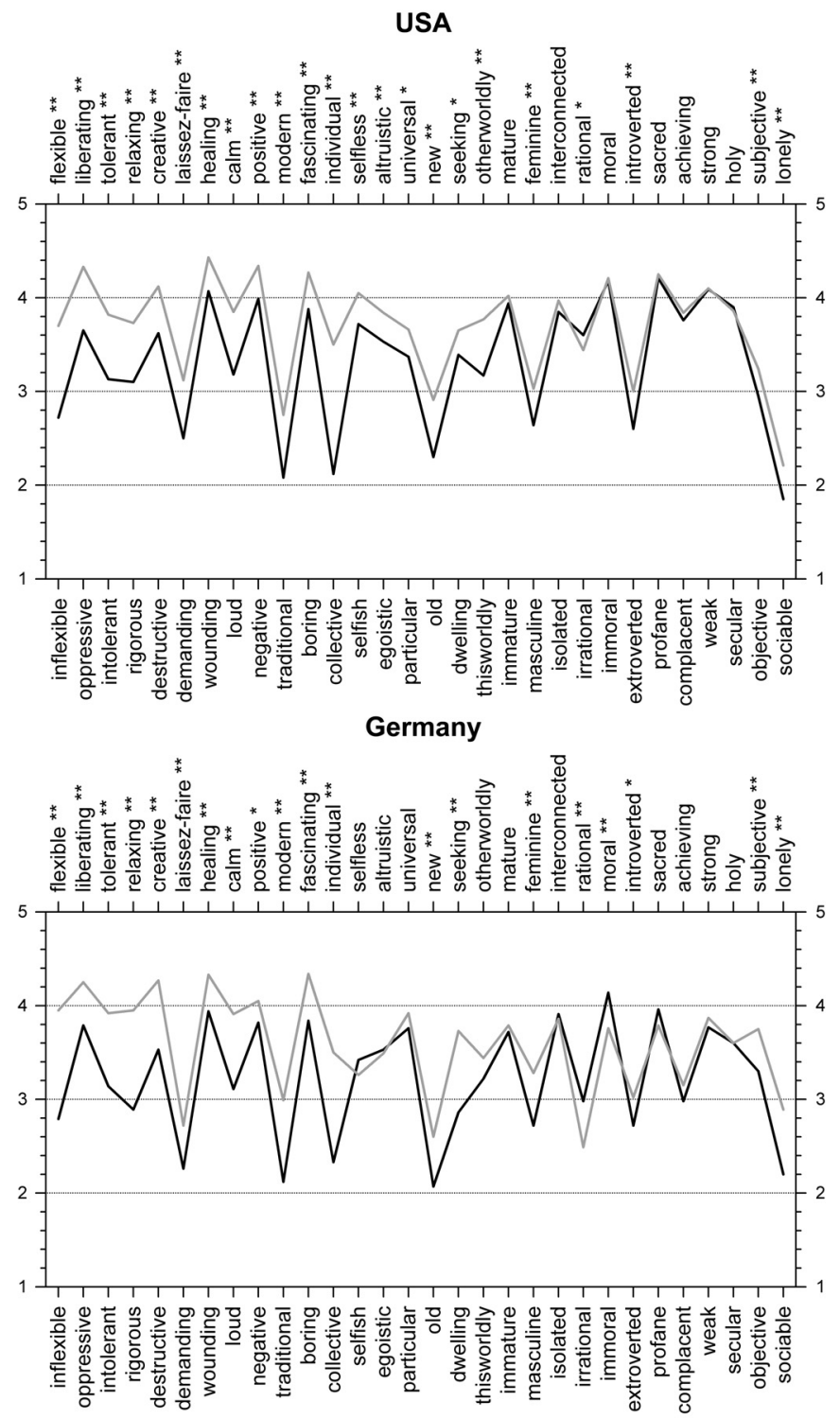

Fig. 7. Highly Religious (Contextual Differentials). The black line shows the polarity profile of 'religion', the grey line shows the polarity profile of 'spirituality' for comparison between the American vs German sub-groups of the respondents self-identifying as Highly Religious (HR). The asterisks show the levels of significance for each paired $t$-test: ${ }^{* *} p<.001,{ }^{*} p<.05$. 
B. Keller et al. I

Archive for the Psychology of Religion 35 (2013) 71-100

USA

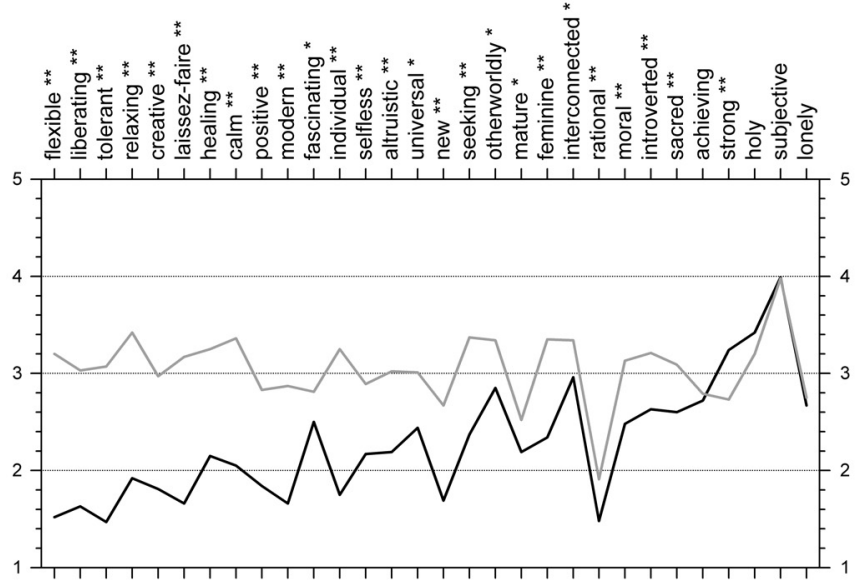

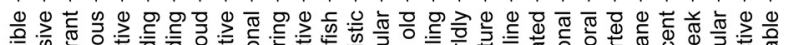

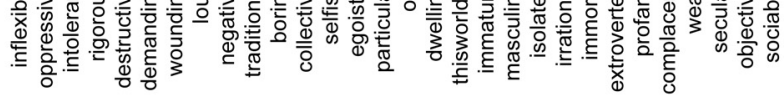

\section{Germany}
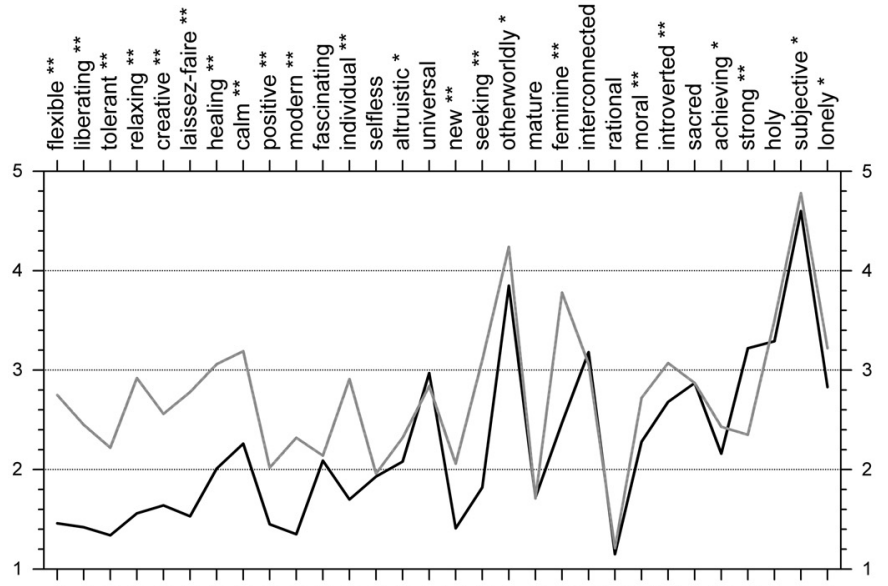

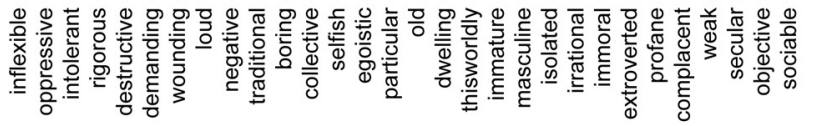

Fig. 8. Neither Spiritual nor Religious (Contextual Differentials). The black line shows the polarity profile of 'religion', the grey line shows the polarity profile of 'spirituality' for comparison between the American vs German subgroups of the respondents self-identifying as Neither Spiritual nor Religious (NSNR). The asterisks show the levels of significance for each paired $t$-test:

$$
{ }^{* *} p<.001,{ }^{*} p<.05 \text {. }
$$




\section{Discussion}

The points of departure of this study were the assumptions that cultural context matters and that one's self-identification as spiritual, religious, or neither has an impact on one's understanding of these terms. This was explored with a cross-cultural design, using the method of the semantic differential, and exploring meanings by evaluating the ratings of connotative adjectives. Data were collected using bipolar scales in a format offered by Osgood and in contextual versions. Results were presented as scatter plots comparing samples by country, and polarity profiles of sub-groups defined by self-identification.

Similarities and differences appear in the general patterns in the semantics of 'religion' and 'spirituality' in the USA and Germany when comparing the scatter plots; the German as well as American respondents seem to conceive the concept 'religion' only as overlapping with what is covered by the term 'spirituality'. Results using Osgood's and the Contextual Semantic Differentials suggest that the concept of 'religion only' seems to fade away from discourse. While, for 'religion only', there appears to be almost nothing left, 'spirituality' seems to have attracted almost every meaning we have asked for. Spirituality emerges as the richer concept by far, especially for American respondents. In the German responses, the Euro-secular tradition, the specific European correlation of modernity and religious decline, may manifest itself in the more critical perspective on both concepts. These findings correspond to the observation that the percentage of people who identify themselves as "more religious than spiritual" is rapidly decreasing, particularly in the USA, while, at the same time, the number of those who identify as either "more spiritual than religious" or "equally religious and spiritual" is increasing (Fuller, 2001; Hood, 2003; Streib et al., 2009). As frequencies of self-identifications in the general population change, both content and range of meanings of the terms 'religion' and 'spirituality' also appear to undergo changes.

More differences become visible when comparing the Highly Spiritual, Low Religious (HSLR), the Highly Religious (HR), and the Neither Spiritual nor Religious (NSNR) sub-groups. For both the German and American HSLR sub-groups, the differences between the concepts 'religion' and 'spirituality' are most pronounced on the Osgood Differentials and on the Contextual Semantic Differentials. Using the Osgood Differentials, 'spirituality' makes a more positive impression and using the Contextual Semantic Differentials 'spirituality' is seen as 'flexible', 'liberating', and 'creative', while 'religion' is seen as 'oppressive', 'intolerant', and 'rigorous'. This mirrors Zinnbauer et al.'s (1997) early findings on experiential spirituality $v$ s organizational religiousness, 
with the addition of a pejorative note. Identifying with "spirituality only" seems to imply taking a stance against religion. This way of handling the concepts is also resonant with the claims of Heelas, Woodhead, Seel, Szerszynski, $\&$ Tusting (2005) that there is a turn away from congregationally organized "life-as religion" (forms of relation to the sacred in which the individual must conform to authority) to "subjective life spirituality" which emphasizes inner sources of significance and internal authority. That in these polarity profiles 'religion' is seen closer to the subjective pole is a counter-intuitive finding deserving further investigation.

In contrast, for the Highly Religious (HR) German and American subsamples, the Osgood polarity profiles for 'spirituality' and 'religion' are aligned, however, not without difference: here 'religion' is more 'old' and 'dark,' while 'spirituality' is 'young' and 'light'. However, the general result of strong similarities between both concepts reflects one of the findings of LaCour, Ausker, $\&$ Hvidt (2012), i.e., the use of 'spirituality' as referring to an integrated part of established religious life. That these differences in the polarity profiles are larger in the German sample suggests that in Germany the term 'spirituality' may be less likely to be used synonymously with 'religion' whereas this seems to be the most common notion within the USA ( $c f$., percentages reported in Table 1). It remains to be seen whether this difference will persist or dissolve with time. The contextual polarity profiles, also aligned, display both 'religion' and 'spirituality' as 'flexible', 'tolerant', 'creative', 'positive', 'fascinating' with 'spirituality' located even closer to those poles, while 'religion' is displayed closer to 'traditional', 'collective', 'old', 'masculine', 'extroverted', and 'sociable'. This also resonates with the reported findings of LaCour $e t$ al. (2012), perhaps also with those of Schlehofer et al. (2008), if we may speculate that most of their older respondents would also have described themselves as religious.

The responses of those participants who identify neither with religion nor spirituality result in different profiles for 'religion' and 'spirituality', but less pronounced than the difference displayed in the Highly Spiritual, Low Religious (HSLR) sub-groups. The Neither Spiritual nor Religious (NSNR) subsamples show more critical views of both religion and spirituality, however, with 'spirituality' looking less negative on both the Osgood and the contextual profile. Both religion and spirituality are seen as 'irrational', more so in the German NSNR sub-sample. This is plausible when we take into account that being 'neither/nor' and displaying critical views on religion is more usual and in line with the cultural mainstream in Germany than in the USA (again refer to data in Table 1). German respondents who identify themselves as 'neither/nor' do not digress so much from the social standards of their cultural 
context and may thus afford more critical views not only on religion but also on spirituality.

The results reported in this article rest on semantic differentials which offered common standards for the quantitative exploration of connotations and denotations of the terms 'spirituality' and 'religion'. This methodological approach has provided the opportunity to show that religious/spiritual self-identification and cultural context matter, profiling culturally situated 'spiritualities'. For further scrutiny, we will relate these results to those of other methods, e.g., the more decisive bottom-up approach of an analysis of our respondents' subjective definitions of 'spirituality' and 'religion' in their free-text entries. Our comprehensive cross-cultural design will also provide interview data in which respondents have more space to display their selfidentifications and worldviews in biographical context. Finally, it will be most interesting to explore personality characteristics, religious schemata, generativity, and other variables as correlates of the different semantic profiles. The comprehensive cross-cultural design of our study will allow the joint inspection of different semantics of 'spirituality' and 'religion' from the perspectives of group- and person-centered, top-down and bottom-up methodologies.

\section{References}

Ahn, G. (1997). Religion I. Religionsgeschichtlich. In Theologische Realenzyklopädie. Bd. 28 (S. 513-522). Berlin: de Gruyter.

Barker, E. (2007) Preface. In B. A. Kosmin, \& A. Keysar (Eds.), Secularism and Secularity. Contemporary International Perspectives Institute for the Study of Secularism in the Society and Culture. (ISSSC) http://prog.trincoll.edu/ISSSC/Book/Chapters.asp (accessed 20 Aug 2010).

Benson, P.L., \& Spilka, B.P. (1973). God-image as a function of self-esteem and locus of control. Journal for the Scientific Study of Religion, 12, 297-310.

Bertelsmann Foundation (Ed.) (2009). What the World Believes: Analysis and Commentary on the Religion Monitor 2008. Gütersloh: Verlag Bertelsmann-Stiftung.

Bianchi, U. (Ed.) (1994). The Notion of 'Religion' in Comparative Research. Selected Proceedings of the XVIth Congress of the International Association for the History of Religions, Rome, 3-8 September 1990. Rom: Bretschneider.

Bortz, J., \& Döring. N. (2006) Forschungsmethoden und Evaluation für Human- und Sozialwissenschafter. Heidelberg: Springer.

Brody, N. (1965). Psychology of the scientist. XIII. Scientific and religious experiences distinguished by their "affect". Psychological Reports, 16, 737-744.

Broughton, W. (1975). Theistic conceptions in American protestantism. Journal for the Scientific Study of Religion, 14, 331-344. 
Büssing, A. (2006). "Spiritualität”-Worüber reden wir? In A. Büssing, T. Ostermann, M. Glöckler, \& P. F. Matthießen (Eds.), Spiritualität, Krankheit und Heilung-Bedeutung und Ausdrucksformen der Spiritualität in der Medizin (pp. 69-84). Frankfurt/Main: Verlag für Akademische Schriften.

Costa, P. T. \& McCrae, R. R. (1985). Revised NEO Personality Inventory (NEO PI-R) and NEO Five-Factor-Inventory (NEO-FFI). Professional Manual. Odessa: Psychological Assessment Resources.

Craddick, R. A., Thumin, F. J., \& Barclay, A. G. (1971). A semantic differential study of the yin-yang symbol. Journal of Personality Assessment, 35, 338-343.

Daiber, K.-F. (2001). Christus-Pavillon und Pavillon der Hoffnung. In W. Lukatis, \& G. Wegner (Eds.), Das Christentum auf der EXPO 2000 (pp. 213-226). Würzburg: Ergon.

Emmons, R. A. (1999). The Psychology of Ultimate Concerns. Motivation and Spirituality in Personality. New York: Guilford.

Fowler, J. W. (1981). Stages of Faith. The Psychology of Human Development and the Quest for Meaning. San Francisco: Harper \& Row.

Fowler, J. W., Streib, H., \& Keller, B. (2004). Manual for Faith Development Research. (3rd edn.) Bielefeld/Atlanta: Research Center for Biographical Studies in Contemporary Religion/ Center for Research in Faith and Moral Development, Emory University [available at: http:// wwwhomes.uni-bielefeld.de/religionsforschung/].

Francis, L. J. (1997). The psychology of gender differences in religion: A review of empirical research. Religion, 27, 81-96.

Francis, L. J., Robbins, M., \& Gibson, H. M. (2006). A revised Semantic Differential Scale distinguishing between negative and positive God images. Journal of Beliefs \& Values, 27, 237-240.

Fuller, R. C. (2001). Spiritual, but not Religious: Understanding Unchurched America. Oxford: Oxford University Press.

GESIS_Leibniz-Institut für Sozialwissenschaften (Ed.) (2008). ALLBUS 2008 (Vollversion). Mannheim: GESIS—Leibniz-Institut für Sozialwissenschaften. Online accessible at: www. gesis.org/dienstleistungen/daten/umfragedaten/allbus/.

Granqvist, P. (2002). Attachment and Religion: An Integrative Developmental Framework. Ph.D. Diss., Avhandlingar från Uppsala Universitet.

Greenwald, D. F., \& Harder, D. W. (2003). The dimensions of spirituality. Psychological Reports, 92, 975-980.

Haußig, H. M. (1999). Der Religionsbegriff in den Religionen. Studien zum Selbst und Religionsverständnis in Hinduismus, Buddhismus, Judentum und Islam. Berlin: Philo.

Heelas, P., Woodhead, L., Seel, B., Szerszynski, B., \& Tusting, K. (2005). The Spiritual Revolution: Why Religion is Giving Way to Spirituality. Oxford: Blackwell.

Heise, D. R. (2010) Surveying Cultures: Discovering Shared Conceptions and Sentiments. Hoboken, NJ: John Wiley.

Hofman, J. E. (1970). The meaning of being a Jew in Israel. An analysis of ethnic identity. Journal of Personality and Social Psychology, 15, 196-202. 
Hofstätter, P. R. (1957). Psychologie. Frankfurt/Main: Fischer.

Hood, R. W. (1973). Dogmatism and opinions about mental illness. Psychological Reports, 32, 1283-1290.

Hood, R. W. (1974). Cognitive and affective rejection of mentally ill persons as a function of dogmatism. Psychological Reports, 35, 543-549.

Hood, R. W. (1975). The construction and preliminary validation of a measure of reported mystical experience. Journal for the Scientific Study of Religion, 14, 29-41.

Hood, R. W. (2003). Spirituality and Religion. In A. L. Greil, \& D. G. Bromley (Eds.), Religion: Critical Approaches to Drawing Boundaries between Sacred and Secular (pp. 241-264). Amsterdam: Elsevier.

Hood, R. W., Hill, P. C., \& Spilka, B. (2009). The Psychology of Religion. An Empirical Approach. New York: Guilford.

Hood, R. W., Morris, R. J., Hickman, S. E., \& Watson, P. J. (1995). Martin and Malcolm as cultural icons: An empirical study comparing lower class African-American and white males. Review of Religious Research, 36, 382-388.

Houtman, D., \& Aupers, S. (2007). The spiritual turn and the decline of tradition: The spread of post-Christian spirituality in 14 Western countries, 1981-2000. Journal for the Scientific Study of Religion, 46, 305-320.

Huber, S. (2002). Religiöse Selbstkonzepte im Spiegel der Repertory Grid-Technik. Wege zum Menschen, 54, 220-230.

LaCour, P., Ausker, N. H., \& Hvidt, N. C. (2012). Six understandings of the word 'spirituality' in a secular country. Archive for the Psychology of Religion, 34, 63-81.

McAdams, D. P., \& de St Aubin, E. D. (1992). A theory of generativity and its assessment through self-report, behavioral acts, and narrative themes in autobiography. Journal of Adult Development, 62, 1003-1015.

Muthen, B., Olsson, U., Pettersson, T., \& Stahlberg, G. (1977). Measuring religious attitudes using the semantic differential technique: An application of three-mode factor analysis. Journal for the Scientific Study of Religion, 16, 275-288.

National Opinion Research Center (Ed.) (2009). General Social Survey 1972-2008 Data File. Chicago: National Opinion Research Center. Online accessible at: www.norc.org/projects/ general+social+survey.htm.

OECD (2011). Education at a Glance 2011. OECD Publishing. Organisation for Economic Co-operation and Development.

OECD Factbook 2011-2012. OECD Publishing.

Osgood, C. E. (1962). Studies on the Generality of affective meaning systems. American Anthropologist, 17, 10-28.

Osgood, C. E. (1972). The nature and measurement of meaning. In J. G. Snider, \& C. E. Osgood (Eds.), Semantic Differential Technique: A Sourcebook (pp. 3-41). Chicago/New York: Aldine/ Atherton. 
Osgood, C. E., May, W. H., \& Miron, M. S. (1975) Cross-cultural Universals of Affective Meaning. Urbana, IL: University of Illinois Press.

Ryff, C. D. (1989). Happiness is everything, or is it? Explorations on the meaning of psychological well-being. Journal of Personality and Social Psychology, 57, 1069-1081.

Ryff, C. D. \& Singer, B. H. (1998). The role of purpose in life and growth in positive human health. In P. T. P. Wong, \& P. S. Fry (Eds.), The Human Quest for Meaning. Handbook of Psychological Research and Clinical Applications (pp. 213-235). Mahwah: Lawrence Erlbaum Associates.

Schlehofer, M. M., Omoto, A. M., \& Adelman, J. R. (2008). How do 'religion' and 'spirituality' differ? Lay definitions among older adults. Journal for the Scientific Study of Religion, 47, 411-425.

Schmitz, B. (1996). 'Religion' und seine Entsprechungen im interkulturellen Bereich. Marburg: Tectum.

Snider, J. G., \& Osgood, C. E. (1972). Semantic Differential Technique: A Sourcebook. Chicago: Aldine (first published in 1969).

Streib, H. (2008). More spiritual than religious: Changes in the religious field require new approaches. In H. Streib, A. Dinter, \& K. Söderblom (Eds.). Lived Religion-Conceptual, Empirical and Practical-Theological Approaches (pp. 53-67). Leiden: Brill.

Streib, H. (in press). Deconversion. In L. R. Rambo, \& C. E. Farhadian (Eds.), Oxford Handbook on Religious Conversion. Oxford: Oxford University Press.

Streib, H., \& Hood, R. W. (2011). "Spirituality" as privatized experience-oriented religion: Empirical and conceptual perspectives. Implicit Religion, 14(4), 433-453.

Streib, H., Hood, R. W., Keller, B., Csöff, R.-M., \& Silver, C. (2009). Deconversion. Qualitative and Quantitative Results from Cross-Cultural Research in Germany and the United States of America. Research in Contemporary Religion 5, Göttingen: Vandenhoeck \& Ruprecht.

Streib, H., Hood, R. W., \& Klein, C. (2010). The Religious Schema Scale: Construction and initial validation of a quantitative measure for religious styles. The International Journal for the Psychology of Religion, 20, 1-22.

Streib, H.. \& Keller, B. (2007). Spirituality and Deconversion: Cross-Cultural Research Results. Paper for the International Conference on Spirituality, Prague 2007-IX-21.

Utsch, M., \& Klein, C. (2011) Bestimmungsversuche für komplexe Begriffe. In C. Klein, H. Berth, \& F. Balck (Eds.), Gesundheit-Religion-Spiritualität. Konzepte, Befunde und Erklärungsansätze (pp. 25-45). Weinheim/Munich: Juventa.

Wood, B. T., Worthington Jr., E. L., Exline, J. J., Yali, A. M., Aten, J. D., \& McMinn, M. R. (2009). Development, refinement, and psychometric properties of the Attitudes toward God Scale (ATGS-9). Psychology of Religion and Spirituality, 2, 148-167.

Woodhead, L. (2007) Gender differences in religious practice and significance. In J. A. Beckford, \& N. J. Demerath III (Eds.), The Sage Handbook of the Sociology of Religion (pp. 566586). Los Angeles: Sage. 
Wulff, D. M. (2009). Something Old, Something New...: The Faith Q-Sort. Paper for the Congress of the International Association for the Psychology of Religion, Vienna 2009-VIII-26.

Zinnbauer, B. J., Pargament, K. I., Cole, B., Rye, M. S., Butter, E. M., Belavich, T. G., Hipp, K. M., Scott, A. B., \& Kadar, J. L. (1997). Religion and spirituality: Unfuzzying the fuzzy. Journal for the Scientific Study of Religion, 36: 549-564. 